Preprint: Final version appears as:

Morgan, R. \& Bull, P. (2007) The use of grain size distribution analysis of sediments and soils in

forensic enquiry. Science and Justice. DOI 10.1016/j.scijus.2007.02.001

\title{
The Use of Grain Size Distribution Analysis of Sediments and Soils in Forensic Enquiry
}

\author{
Morgan, R. M and Bull, P. A.
}

Oxford University Centre for the Environment, Dyson Perrins Building, South Parks Road, Oxford, OX1 3QY

Communicating author: Ruth Morgan

Ruth.morgan@ucl.ac.uk

Tel: +442031083037

Fax: +442031083088 


\title{
The Use of Grain Size Distribution Analysis of Sediments and Soils in Forensic Enquiry
}

\author{
Morgan, R. M and Bull, P. A. \\ Oxford University Centre for the Environment, Dyson Perrins Building, South Parks \\ Road, Oxford, OX1 3QY
}

\begin{abstract}
The use of grain size distribution analysis in forensic enquiry was investigated with reference to four forensic case studies which contained the type of sample restraints and limitations often encountered in criminal case work. The problems of the comparison of trace and bulk samples are outlined and the need for multiple sample analysis is highlighted. It was found that the problems of soil analysis, particularly when the soil was recovered from anthropogenic sources, focussed on the lack of identification of pre-, syn- and post-forensic event mixing of materials, thus obscuring the recognition of false-negative or false-positive exclusions between samples. It was found that grain size distribution analysis was a useful descriptive tool but it was concluded that if it were to be used in any other manner the derived results should be treated with great caution. The statistical analyses of these data did not improve the quality of the interpretation of the results.
\end{abstract}

Keywords: Forensic Science; Grain size distribution analysis, sediments and soils. 


\section{Introduction}

One of the fundamental and most ubiquitous tests undertaken during the analysis of sediments and soils in geological investigations is that of grain size distribution analysis (for example [1] [2] [3] [4]). The various size ranges and proportions of material identified during grain size distribution analysis encompass materials of submicron size through clays, silts, sands and gravels. Whilst a variety of different techniques have been employed during geological analyses to present these distributions ([5] [6]), the ultimate aim of the researcher has been to describe the sediment and provide some environmental or palaeoenvironmental information as to the mechanisms by which the deposit has been transported and deposited to its final resting place ([1]). Grain size distribution analysis is now being employed routinely during forensic casework analysis ([7] [8]) although it will be shown in this paper that there are problems in using this well-established geological technique in forensic investigation in any way other than as a descriptive mechanism.

The characteristics identified by analysing the grain size distribution of a sample are dependent on a number of controlling factors irrespective of whether we are investigating geological or forensic samples. Initially, the make-up of the grain size distribution of a sample depends upon the make-up of the grain size distribution of the source materials. This may be another sediment sample, or indeed be the weathered or eroded product of a rock strata. The transportation of the sediment from its source or sources will further affect the grain size distribution of the final sample. The mechanism of transportation (wind, water, or gravity) will winnow the various sediments in accord with the capabilities of the energy conditions of transportation. Finally, the grain size distribution of a sediment will be dependent upon the syn- and post-depositional processes which prevail (winnowing, pedogenesis, chemical alteration etc.). Another factor complicates the issue. A soil is a three dimensional structure comprising discrete sedimentary and pedogenic layers. The individual layers often have very different grain size distribution characteristics. A sediment body may also reflect temporal variations in deposition which are recorded in grain size distribution variations down-section. As will be illustrated later, it can be very foolhardy to compare the grain size distribution of a sediment taken from a taping, a trace sample and a $1 \mathrm{~kg}$ bulk sample without exercising great caution in the 
interpretation of the results. All three samples may derive from the same geographic location but all may differ fundamentally in their grain size distribution with the possibility of subsequent interpretation producing a false-negative result [9].

Forensic enquiry however, takes this complicated relationship a little further. The grain size distribution of a forensic sample must now take into account alteration and mixing of soil from different sources caused by the movement of the material by anthropogenic effects on footwear, clothing and vehicles. Thus, not only is there a complication of mixing to consider in forensic enquiry but there is also the thorny issue of selective transfer, persistence and decay of materials which will alter the grain size distribution curve further [10].

The forensic scientist must ask why they wish to undertake grain size distribution analysis of a sample. Here, the ultimate aim is to compare a number of samples of soil or sediment from a suspect or their belongings with a comparator group of samples located at or about a forensic incident or scene of enquiry. Fundamentally, the forensic geoscientist seeks to exclude samples from having been derived from the comparator source ([11] [12]). Analysis is therefore descriptive (as is often the case with geological enquiry) or on occasion exclusionary. Samples that are analysed by descriptive analytical techniques may, due to their differences identified by that descriptive technique, be exclusionary and/or diagnostic in nature. If two samples are, for example, different in colour, they can be considered exclusionary and so the descriptive technique becomes diagnostic. However, if two samples have the same descriptive characteristics (for example, colour) it cannot be argued with any sense of propriety that the samples are diagnostically similar and therefore must be related by provenance to each other.

Similarly, two soil samples that are compared in a forensic investigation may exhibit very similar grain size distributions. This may be due to the fact that they are derived from a very similar provenance but may equally be due to having been derived from different locations with a similar environmental history. Likewise, the two samples may exhibit different grain size distributions even if they have derived from the same source due to the 'three-dimensional nature of the soil profile' mentioned above or 
indeed due to different sample sizes being compared to each other; for example $1 \mathrm{~g}$ of soil compared to $1 \mathrm{~kg}$ of bulk sample from the same source.

So grain size distribution analysis has many of the same pitfalls as the descriptive technique of colour analysis, although this does not stop the publishing of reviews of grain size distribution analysis in the forensic literature ([7] [8]). Equally, the transposition of the geological interpretations and parameters using grain size distribution analysis do not fit well in many of the exploratory studies which investigate the efficacy of grain size distribution analysis in forensic situations. Some authors have acknowledged the difference between geological and forensic approaches and have attempted to assimilate their experimental work to approximate real forensic case situations ([13]). There appears to be no merit in highlighting the ability of a new, or even an old analytical technique for grain size distribution analysis using obviously different samples, taken from grossly different environments, often many miles apart ([14]). It should be remembered that the quality of the results are matched only by the quality of the input ([15]).

The intention of this paper is to review the claims of the current literature on forensic applications of grain size distribution analysis and to provide casework examples where grain size distribution can provide some interesting and sometimes compelling interpretations useful in forensic enquiry. Some of the examples however, illustrate false-positive results and so provide a cautionary tale.

\section{A Literature Review}

Grain size distribution analysis of a soil or sediment sample by means of sieving was introduced into the forensic science literature as early as 1956 ([11] and [16]) as a well established geological technique ([1] [4] and [17]). As is the case with many of the 'borrowed' analytical techniques that have been applied to forensic investigation, a relatively large sample size (in the order of grams) is required for accurate and reproducible results to be obtained compared to what is usually available in forensic analysis. Dudley [18] pointed out in 1977 that the amount of sediment available in a forensic sample will generally preclude such geological techniques from being 
employed in routine forensic science analysis. He went on to propose a method for establishing particle size distribution of soil and sediment samples using a Coulter Counter, which was able to provide reproducible results for smaller quantities of sample (200mg), and to provide discriminatory power between samples from different sources. Now there are a whole range of laser granulometers which can, at least for the same machine, reproduce grain size distribution curves from very small amounts of material (less than 10mg) which in itself provides further problems for the forensic analyst (see section 3.4).

The early work of Dudley was developed by Wanogho et al. ([19] [20]) who demonstrated that it was possible to establish soil sample discrimination and provenance by comparing the median particle size, modal class interval of particle size and percentage of organic matter of different soil samples. Further work produced greater discrimination between samples by using a combination of the Coulter Counter and Automated Image Analysis systems in the analysis of samples. More recently still, Murray and Solebello [17] advocated direct observation and measurement by microscopy for forensic grain size distribution analysis.

Junger [21] and Sugita and Marumo [22] have both demonstrated the benefits of using grain size distribution analysis in combination with other analytical techniques in the quest to provide discrimination between samples. They showed that by utilising both colour analysis and grain size distribution analysis that soil samples from a particular geological area could be distinguished. These works however, are both based on experimental studies and may not approximate forensic casework reality. Restrictions such as limited sample size and mixing from a variety of different host materials and sources are not taken into account. Using either or both of the techniques of grain size distribution and colour it would prove practically impossible to determine whether pre- or post-event mixing of materials had taken place in a real case forensic scenario rather than having experimental a priori knowledge. This is due to the need to homogenise the materials prior to analysis by both colour and grain size distribution techniques.

More recently still, there have been a number of papers published on the application of particle size distribution analysis to the analysis of soil and sediment samples in 
forensic investigations ([7] [8] [13] and [14]). These papers have generally all provided the results of experimental studies (using both laser granulometry and sieving techniques) and have demonstrated, in the first instance, that it is possible to distinguish between soil and sediment samples taken from distinct geological areas. It is particularly interesting to note that when 'simple transfers' of soil from a source area onto an item of footwear are simulated under laboratory conditions, it has been discovered that both the particle size distribution of the source soil and the type of footwear can significantly affect the particle size distribution of the transferred soil sample subsequently taken from the shoe ([13] and [14]). Chazottes et al. [13] showed that if a source soil sample has a unimodal particle size distribution of siltsized particles, the particle size distribution of the transferred soil sample, taken from the footwear, was more similar to the particle size distribution of the source soil sample. If however, the source sample had a bi-modal particle size distribution rich in fine (clay-sized) and coarse (sand-sized) particles, the particle size distribution of the transferred soil was found to be significantly different to that of the source soil. This is because clay and silt-sized particles appeared to be poorly represented in the transferred soil samples. Croft and Pye [14] also identified the selective nature of transfer of various size ranges of particles onto footwear, however, neither Croft and Pye [14] nor Chazottes et al. [13] identified the implications of these findings to exclusion enquiries in forensic investigation ([12]). These findings ([12] [13] [14]) raise significant questions as to the efficacy of grain size distribution analysis as a comparative tool in certain forensic investigations. It may not always be appropriate to employ grain size distribution analysis on samples that have undergone some sort of transfer when attempting to compare them to, and so exclude them from, potential soil sample sources. The limited number of forensic case examples that are provided in the literature demonstrate the ability of this technique to provide comparative results to show similarity or dissimilarity between forensic soil and sediment samples in particular situations. There seem to be no case examples where grain size distribution analysis has been shown to be an inappropriate technique, or where such analysis has provided false-positive results. 


\section{Case studies}

\subsection{Introduction}

We acknowledge the necessity for experimental work under controlled conditions to determine the efficiency of a new technique for forensic enquiry, although we suggest that the results of the experimental work for forensic application might be misleading when the technique is long established in a comparative scientific discipline. The constraints of analysis in real casework situations do in effect require adaptation and compromise in almost every new case that arises. There is then a dilemma between upholding the forensic principles of exclusion, description and diagnosis whilst using a new technique which may involve the analysis of very small amounts of material. Does the analysis of a trace amount of material reflect the characteristics of the materials taken from the original sediment body? The answer to this question, of course, concerns the normal problems identified in the statistical appraisal of geological analysis when we consider sample size and sediment population size. Therefore, with these caveats in mind we provide the results of a number of casework studies which show lessons to be learned at micro-, meso- and macro-scale. None of the case studies provided herein were investigated using only grain size distribution analysis. Other independent physical and chemical analytical techniques were used in all cases and some of their results agreed and some disagreed with the results obtained from this grain size distribution analysis. The inclusion of their results is beyond the remit of this paper.

\subsection{A case of suspected badger baiting}

A suspect was arrested on a road close to a badger sett that had been dug up in order to gain access to the badgers which could then be set upon by dogs. Two muddy spades were seized from the vehicle belonging to the suspect. In order that comparison could be made between soil from the spades and from the soil at the badger sett, a soil sample was also taken from the badger sett (all samples were collected by the Scene of Crime Officer). It was inevitable however, that this material 
was collected from a very disturbed site and may have incorporated a mixture of soil from the surface and from a deeper horizon.

If the soil collected from the spades was to be compared to the material at the highly disturbed badger sett, then account would have to be taken of the varied grain size distribution of materials from the different soil horizons which would have derived from the surface and at depth in the sett. To this end ten sub-samples (approximately $1 \mathrm{~g}$ each) were taken from the bulk soil sample (approximately $1 \mathrm{~kg}$ ) taken from the badger sett.

The two spades had appreciable quantities (in forensic terms) of sediment present on them (Figures 1 and 2). The spades were each subdivided into twenty specific areas (see Figures 1 and 2) and a sub-sample of material was taken from each area, thus forty samples were taken in total. (Sub-samples varied between 100mg and $1 \mathrm{~g}$ in weight).

Grain size distribution analysis using a CILAS 920 laser granulometer was undertaken to compare the soil samples taken from the two spades with the soil taken from the badger sett site. All sample preparation techniques employed conformed to standard procedures [7]. Of the twenty samples taken from both spade 1 and 2, twelve of the samples from spade 1 and eleven of the samples from spade 2 were of a sufficient quantity for grain size distribution analysis.

There was a noticeable variation in the particle size distribution of the sub-samples taken from the badger sett site (see Table 1), and from spade 2 (Table 2). The particle size distribution of the eleven soil samples taken from spade 1 appeared to be more similar (see Table 3). However, when an independent two-tailed t-test was undertaken (using SPSS for Windows 11.1) to compare the mean particle size, sorting, skewness and kurtosis no significant differences were identified at the $95 \%$ significance level between the samples taken from the site, spade 1 and spade 2 .

The samples analysed from the badger sett consisted of ten sub-samples and these produced two distinctive curves which may be accounted for by the relative depths that the two groups of analysed samples had derived from in nature. The act of 
digging into the badger sett required disturbing the three-dimensional nature of the soil profile and thus, the repeated analysis of the sub-samples was able to detect two distinctively different curve characteristics. These are portrayed in Figure 3 (A and B).

The grain size distribution analysis from spade 1 (Figures 1, 3 (E) and Table 2) provided one distinctive curve from all twelve sub-samples taken and this curve was most similar to one of the two curves identified at the site of the disturbed badger sett. Apart from noting the similarity of the curves this analysis may identify a lack of mixing of the grain size distribution curve from materials that could have been present on the spade prior (or subsequent) to the incident at the badger sett.

The eleven sub-samples analysed from spade 2 (Figures 2, 3 (C and D) and Table 3) showed two distinctive curves which have a similarity with the two curves identified from the badger sett site samples. Only by undertaking analysis of multiple subsamples of the sediment from the sett and the spades could these two distinctive curves be identified, and the possibility of false-negative interpretations reduced. Whilst the similarity of curves between spade 2 and the badger sett can be noted and confirmed by statistical comparison (see above), there is no further worthy interpretation possible using this technique in this case. Other independent means of forensic analysis would need to be employed (for further details see [23]).

The lesson to be learned here is that meaningful comparison between samples requires comparable samples to be collected in the first instance. This has implications for the collection procedures taught to prospective scenes of crime officers; surface soil samples can only be compared to other surface soil samples. Indeed, $1 \mathrm{~g}$ of material should not be compared to $100 \mathrm{~g}$ of material if comparable results are desired from grain size distribution analysis. Indeed, statistical comparisons between soil samples from different locations should be interpreted with caution.

\subsection{A case of a vehicle hit-and-run}

A large lorry turned out from a side road onto a main dual carriageway and the rear wheels of the lorry mounted the pavement running over a pedestrian who was waiting 
on that corner. A short distance down the road, a lorry of matching description to that which caused the incident was stopped and the driver was questioned. Samples from underneath the vehicle were collected and provided for comparison with debris collected at the scene, which was thought to have fallen from the underside of the vehicle when the pedestrian was hit. Amongst a number of techniques conducted on these sediments was grain size distribution analysis. It was thought that comparison would be meaningful since the underside of the lorry obviously had the same journey history, and would have been subject to the same deposition events leading to the accumulation of a discrete, distinctive sediment body. Furthermore, the lorry had travelled only a mile or two down the road since the incident and this reduced the ambit for mixing to occur to the material still present underneath the lorry. Therefore, material from the underside of the lorry was compared with material that had fallen onto the road; unusually, a like with like comparison could be made (Table 4 and Figure 4). Whilst there is a broad similarity between the grain size distribution curves and proportions of sand silt and clay present in each sample, inspection of the mean size, degree of sorting, skewness and kurtosis values for each sample demonstrates that there is a degree of variability. However, to compute standard deviation and coefficient of variance values would be meaningless as, in this case only 3 samples are available for comparison.

The results derived from other independent analytical techniques could not exclude the material from the vehicle from having derived from the same source as the material recovered from the crime scene, however, the results derived from the grain size distribution analysis could not confirm this conclusion. Whilst a broad similarity could be noted, it was not possible to provide any further conclusions for the court as to the possibility of excluding the material recovered from the crime scene as having derived from a similar provenance to the material recovered from the vehicle.

This hit-and-run example involved a direct 'like with like' comparison between samples and due to the nature of the case, the possibility of subsequent mixing to either group of samples was severely reduced. However, even in this relatively simple case, due to the requirement to homogenise the samples for grain size distribution analysis there is still the possibility of producing a false-negative result in 
our case, particularly if any mixing did occur to either group of samples. There is no simple way of testing this using only grain size distribution analysis.

This example contrasts with another hit and run case documented in the forensic science literature ([7] [8]). In this case sediment samples taken from the nearside and offside of a vehicle were compared to soil samples taken from two grassy verges (nearside and offside) at the scene of the crime. In contrast to our example it was not possible to undertake a 'like with like' comparison between samples and thus there is a high possibility that the samples taken from the grassy verges (single provenance) may have been compared with mixed source samples taken from the sides of the vehicle. In this case it was found that it was not possible to exclude the samples taken from the vehicle from having derived from the same source as the samples taken from the crime scene. However, the possibility in this instance of achieving a falsenegative result is considerable due to the inability of the grain size distribution technique to identify potentially mixed source samples. Furthermore, these two hitand-run cases demonstrate that whilst grain size distribution analysis may provide useful information in one case, it may not necessarily do so in another not withstanding the potential for samples of mixed source to be involved.

\subsection{A case of winnowed deposits}

The naked body of a young woman was found $10 \mathrm{~m}$ from a metalled road on a wooded slope. The very wet conditions of the night, during which she was deposited on the slope, served to remove much of the trace evidence at and about the scene of the body which was discovered no more than nine or ten hours after deposition. The body had been covered by the clothing belonging to the victim which prevented the rain from disturbing any potential forensic evidence on the body. Inspection of the crime scene photographs of the body in situ (minus the covering of clothes) identified that the victim, who was lying face down on the ground, also had mud on the backs of her legs, buttocks and torso. The muddy material on the torso showed discrete contact marks where the naked body had been lying on its back on muddy ground with its arms laid on the ground. 
Grain size distribution analysis (in this case, due to the trace nature of the material, direct measurements of grain diameters were undertaken by scanning electron microscopy) of the material taken from the victim's back provided a mean grain size diameter of $30.91 \mu \mathrm{m}$, whilst the mean grain size diameter of the sediment at the body site was $85.9 \mu \mathrm{m}$. The material on the back of the body was winnowed, finer grained materials which could be shown by other analyses to have derived from about the body site some $10 \mathrm{~m}$ away. A reconstruction may suggest that the body, already at least naked on the back and arms, was dropped onto the road prior to being lifted and laid face down at the deposition site. This simple scenario helped reconstruct the events of the night immediately prior to the deposition of the body and, in conjunction with other analyses, suggested specific post mortem activity. Whilst the winnowed material found on the back of the body could not be excluded from having derived from the same source as the sediment from the body site, grain size distribution analysis alone could not prove that the samples had derived from the same provenance. Grain size distribution analysis simply indicated a rainwash winnowing of materials over a $10 \mathrm{~m}$ distance with an inference of post mortem activity.

The lesson to be learned from this case is that grain size distribution analysis can be used as a descriptive reconstruction technique, but can only be effected if the body is not routinely washed in the mortuary prior to the post-mortem. This case also highlights the necessity for flexibility in grain size distribution analysis techniques and requires forethought rather than rigid routine to be exercised.

\subsection{A multivariate analysis of grain size distribution data}

The body of a girl was found on a dirt path near the top of a wooded hill ridge some $10 \mathrm{~m}$ from a road. The path and road were used regularly by many people as a short cut to and from a flat grassy playing field some $30 \mathrm{~m}$ below the hill ridge. Analysis of soil samples taken from near the body deposition scene, throughout the wooded hill ridge and across a large area of the grassy playing field, was carried out and, as part of the investigation, grain size distribution analysis was undertaken on 43 samples using 
laser granulometry (all necessary preparation techniques were conducted according to the usual protocols [7]).

Subsequent police investigations identified that the victim may well have been seen in one specific area of the playing field talking to an older person. This person became a primary police suspect. Analysis of the soil material taken from the shoes of the suspect and the victim were, together with all the other samples, subjected to a series of geological investigative procedures (elemental chemistry, electron microscopy of quartz grain surface textures, pollen analysis, magnetic resonance and various other binocular and descriptive techniques). The results obtained from the comparison between the samples taken from the hill ridge and the body site with those taken in the playing fields showed very little exclusionary information. This was thought to be due to the similarity of the geological features underlying both the hill and the playing field and the similarity between the organic components of the soils from the hill and the playing fields which were mixed due to a combination of rain wash and repeated foot trampling. Grain size distribution analysis undertaken on all of the samples was subjected to hierarchical cluster analysis (average linkage) in order to determine the similarity or dissimilarity of sample groupings based on grain size distribution in a sample. The derived dendrogram, provided in Figure 5 and summarised in Table 5, shows that there is a predominance of groupings of samples taken from the suspect $(100 \%)$ together with samples taken from the path leading to the body deposition site $(77.8 \%)$. There is only a small association with the field (5.9\%) and other areas of the hill (11.1\%) (Figure 5 group B and Table 5). This compares markedly with the clustering from group A where the one sample taken from the shoes of the victim is found to be grouped with the majority of the samples taken from the field (94.1\%) and the hill/body deposition site $(88.9 \%)$ but only with $22.2 \%$ of the samples taken from the path to the body deposition site. Canonical Discriminant Function analysis was undertaken to ascertain whether the two groups identified by the hierarchical cluster analysis (average linkage) were statistically significant. One factor accounted for $100 \%$ of the variance and discrimination of the two groups and this was significant at the $95 \%$ significance level $(0.00<0.05$ (see Table 6)). From this analysis the scenario could be postulated that the victim did not use the path but had been in the field prior to being deposited at the body deposition site. In other words, the victim must have been carried up the slope. 
One could make a reasonable case of association given the large number of samples analysed ( $n=43)$, for the shoes of the suspect and the hill (particularly the body site) and for the mud from the shoes of the victim with that of the field below the hill ridge. But is there any test to check whether this is a false interpretation? No other forensic test undertaken on the mud samples could differentiate the samples taken from the shoes of the victim with that specific area in the field where the victim was last seen. No association or exclusion was identified from visual inspection of the grain size distribution curves, or from simple comparison of the mean and mode grain size values of the samples. Since there was no other corroborative technique, it would be unwise to proceed with what could well be an incorrect interpretation. Grain size distribution analysis was really only able to suggest two points; firstly that it was unlikely that the girl walked up the slope to where the body was eventually found and secondly that perhaps the suspect may indeed have been on the hill.

The reason for caution over the reliance on such 'black box' analysis can be found in the constraints and rationale of studying the transference and persistence of mud on shoes. Although full discussion of this problem is beyond the remit of this particular paper, it is sufficient to identify the problems of sediment mixing before, during and after a forensic incident. Prior to the death of the victim, it is possible that both she and the suspect had picked up soil from a number of other sites unrelated with this case. It is equally possible that their shoes were clean and that they walked on the metalled paths and roads. At some stage however, both victim and suspect must have collected soil from a specific site and at least one of them collected mud on their shoes as they climbed the dirt path to the body deposition site. Following the deposition of the body the suspect may have retraced their steps along the muddy pathways, or exited the wooded area to make good their escape along a metalled road. Perhaps the mixture of materials from different sites fortuitously provided a positive association between samples. In any event, the deposition of material on a shoe is a complex association and its decay from the shoe even more so ([12]).

With reference to the geological interpretation of the grain size distribution of soil and sediment materials on the hill ridge and the field, it would indeed be fortuitous if there 
was a completely different grain size distribution not only characteristic of either the field area or the hill areas, but also distinctly different from each other as seems to be provided in Figure 5. Although in this case separation between the cluster groups could be identified from grain size distribution analysis and be interpreted to provide a meaningful reconstruction of events, this interpretation is very much open to question. No amount of statistical verification of the groupings will provide proof of the validity of any interpretation. Grain size distribution analysis is not intended to identify diagnostic similarities. It is best used as an exclusionary, or indeed even as a merely descriptive technique.

Lessons to be learned from this case are firstly, that more than one independent technique should be employed wherever possible (and the main technique should not just be grain size distribution analysis) and secondly, that to rely on multi-variate black box statistical packages requires an appreciation of the quality of the generated data, and perhaps a degree of a priori knowledge.

\section{Conclusions}

This paper set out to evaluate the use of grain size distribution analysis of sediments and soils in situations which involved the real restraints and limitations found in actual forensic cases. The evaluation of the efficacy of the techniques of grain size distribution analysis is framed within the forensic philosophy of exclusion as once outlined by Walls [11].

Whilst acknowledging that each case brings with it its own set of circumstances, a series of lessons have been learned with reference to the four cases provided in this paper:

1. Meaningful comparison between samples analysed for grain size distribution requires comparable samples to be collected in the first place. Bulk samples of soil (a three-dimensional structure in itself) may contain discrete and coherent units of sediment which exhibit different grain size 
distribution characteristics. To compare these bulk samples with trace materials taken, in this instance from shovels, requires multiple sample analysis to identify the variation and hence effect a proper comparison.

2. Grain size distribution analysis (manual or automated) involves homogenising the sample prior to analysis and this will obscure any mixing that may have occurred before or after the forensic incident. False associations or exclusions will occur and there is no method of identifying this by grain size distribution analysis alone. Indeed, similar issues can be found with reference to some forms of chemical analysis used in forensic investigations ([25])

3. Grain size distribution analysis can in some instances be used effectively to reconstruct events which take place over a very small area.

4. Multi-variate statistical analysis can produce compelling similarities and exclusions from gross data matrices. Unless there is a meaningful explanation for these comparisons and unless there is corroborative evidence from independent forensic techniques, great caution should be observed in deriving any interpretation of the results.

\section{Acknowledgements}

The authors would like to acknowledge discussion and comments with Adrian Parker, Chris Jackson and Matthew Morgan. RM acknowledges financial support from the Bruce, Julia and Mortimer May Senior Scholarship at Hertford College Oxford. The authors would also like to thank two anonymous referees who provided very insightful comments in response to an earlier draft of this paper.

\section{References}

[1]Nichols, G. Sedimentology and Stratigraphy. Blackwell Science Ltd. Oxford, 1999.

[2]Lewis, D. G and McConchie, D. Practical Sedimentology. Chapman and Hall, 1994a. 
[3]Lewis, D. G and McConchie, D. Analytical Sedimentology. Chapman and Hall, 1994b.

[4]Pettijohn, F. J., Potter, P. E. and Siever, R. Sand and Sandstone. Springer-Verlag Berlin Heidelberg NewYork, 1972.

[5]Krumbein, W. C. Size frequency distribution of sediments. Journal of Sedimentary Petrology 1934; 4:65-77

[6]Folk, R.L A review of grain-size parameters. Sedimentology 1966; 6:73-93 [7]Blott, S. J., Croft, D. J., Pye, K., Saye, S. E. and Wilson, H. E. Particle size analysis by laser diffraction. From Pye, K. and Croft, D.J. (Eds.). Forensic Geoscience - Principles, Techniques and Applications. Geological Society Special Publication No. 232, Geological Society Publishing House, Bath, 2004.

[8]Pye, K. and Blott, S. J. Particle size analysis of sediments, soils and related particulate materials for forensic purposes using laser granulometry. Forensic Science International 2004; 144 (1):19-27

[9] Morgan, R. M., Wiltshire, P., Parker, A. and Bull, P. A. The role of forensic geoscience in wildlife crime detection. Forensic Science International. 2006 162: $152-162$

[10] Bull, P. A., Morgan, R. M., Sagovsky, A. and Hughes, G. J. A. The Transfer and Persistence of Trace Particulates: Experimental studies using clothing fabrics.

Science and Justice. 2006 46(3): 182-192

[11]Walls, H.J. Forensic Science. London: Sweet and Maxwell, 1968.

[12]Bull, P. A., Morgan, R. M., Wilson, H. E. and Dunkerley, S. Multi-technique comparison of source and primary transfer soil samples: an experimental investigation' by D Croft and K Pye [1]. A Comment. Science and Justice 2004; 44(3):173-176

[13]Chazottes,V., Brocard, C. and Peyrot, B. Particle size analysis of soils under simulated scene of crime conditions: the interest of multivariate analyses. Forensic Science International 2004; 140, (2-3) :159-166

[14]Croft, D. J. and Pye, K. Multi-technique comparison of source and primary transfer soil samples: an experimental investigation. Science and Justice 2004; 44 (1):21-28.

[15]Davis, J. C. Statistics and Data Analysis in Geology. New York, John Wiley and Sons Inc, 1973. 
[16]Nickolls, L. C. The Scientific Investigation of Crime. London: Butterworth \& Co. Ltd, 1956.

[17]Murray, R. C. and Solebello, L. P. In Saferstein, R. (ed) Forensic Science Handbook volume I. Prentice-Hall. Upper Saddle River, New Jersey, 2002.

[18]Dudley, R. J. The Particle Size Analysis of Soils and its Use in Forensic Science - The Determination of Particle size Distribution Within the Silt and Sand Fractions. Journal of the Forensic Science Society 1977; 16:219-229.

[19]Wanogho, S. and Caddy, B. A Statistical Method for Assessing Soil

Comparisons. Journal of Forensic Sciences 1985; 30(3): 864-873.

[20]Wanogho S, Gettinby G, Caddy B, Robertson J. Determination of Particle Size Distribution of Soils in Forensic Science Using Classical and Modern Instrumental Methods. Journal of Forensic Sciences 1989; 34(4):823-835.

[21]Junger, E. P. Assessing the unique characteristics of close-proximity soil samples: just how useful is soil evidence? Journal of Forensic Science 1996; 41(1): 27-34.

[22]Sugita, R. and Marumo, Y. Screening of soil evidence by a combination of simple techniques: validity of particle size distribution. Forensic Science International 2001; 122: 155-158.

[23] Morgan, R. M. Forensic Geoscience: sedimentary materials in forensic enquiry. 2006 Unpublished D.Phil thesis, University of Oxford.

[24]Blott, S. J. and Pye, K. GRADISTAT: a grain size distribution and statistics package for the analysis of unconsolidated sediments. Earth Surface Processes and Landforms 2001; 26: 1237-1248.

[25] Morgan, R. M. and Bull, P. A.Data interpretation in forensic sediment geochemistry. Environmental Forensics 2006; 7:1-10 


\section{List of Figures}

Figure 1 Spade 1 showing adhering mud and the twenty sample sites collected for grain size analysis.

Figure 2 Spade 2 showing adhering mud and the twenty sample sites collected for grain size analysis.

Figure 3 Grain size distribution histograms and cumulative curves portraying the two types of grain size distribution found at A and B: the badger sett site; C and D: spade 2; and E: spade 1.

Figure 4 Grain size distribution curves for the sample from the vehicle (top) and the samples from the crime scene (middle and bottom).

Figure 5 Dendrogram computed from grain size distribution analysis of samples from the hill ridge, the hill path, the field, the suspect, the shoe from the victim and from exclusionary samples. $n=43$.

\section{List of Tables}

Table 1 Grain size distribution data for sediment samples derived from the badger sett site (modified from GRADISTAT [24]).

Table 2 Grain size distribution data for sediment samples derived from spade 2 (modified from GRADISTAT [24]).

Table 3 Grain size distribution data for sediment samples derived from spade 1 (modified from GRADISTAT [24]).

Table 4 Grain size distribution data for sediment samples derived from both vehicle and incident site (modified from GRADISTAT [24]).

Table 5 Summary of the locations of samples in each of the two groupings from the dendrogram, Figure 5. Figures in brackets indicate the percentage of samples from each location in each cluster grouping.

Table 6 Summary of the CDF analysis (computed by SPSS 11.4 for Windows) undertaken to assess the statistical significance of Groups A and B derived in Figure 5 . 


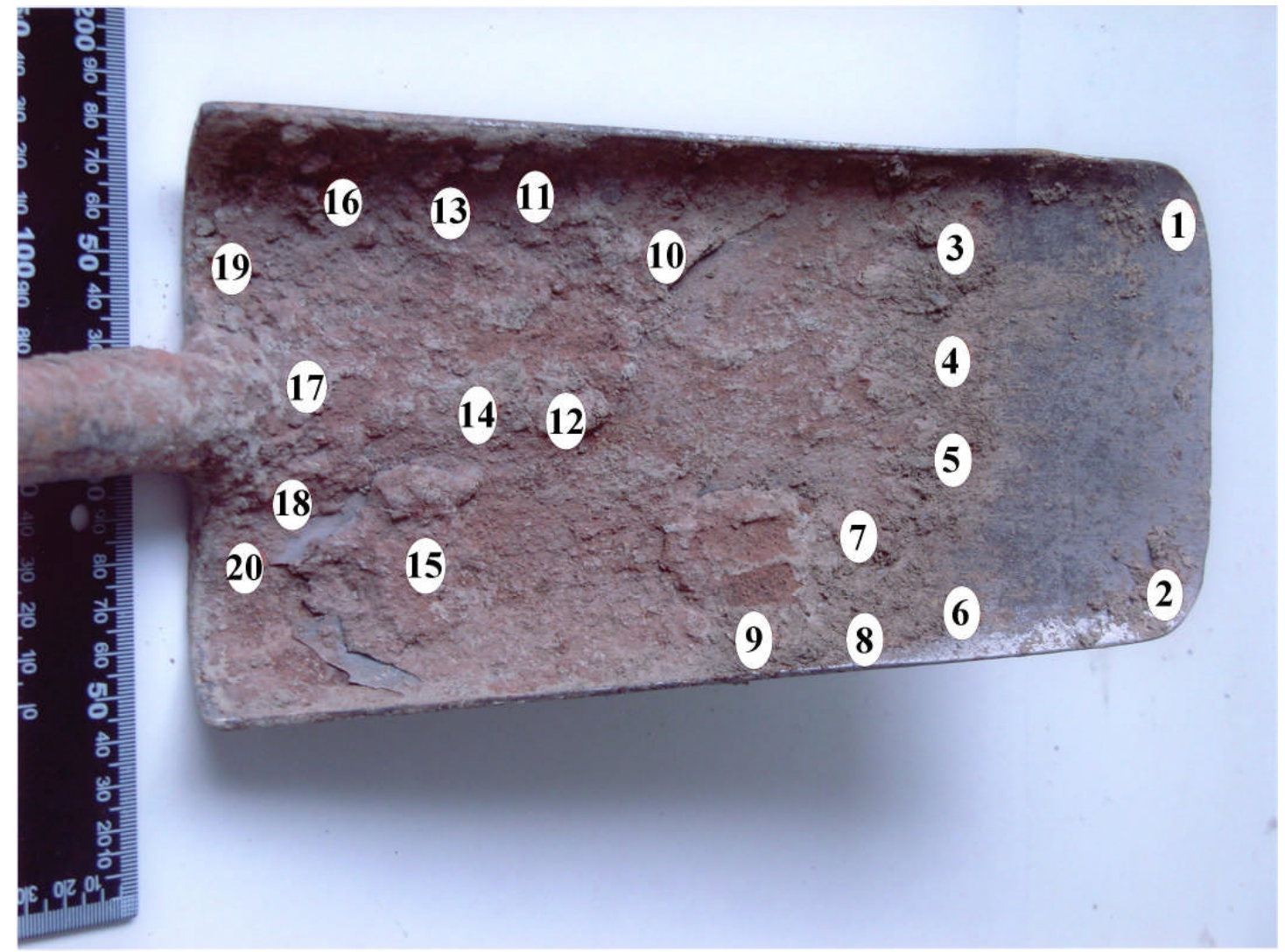

Figure 1 Spade 1 showing adhering mud and the twenty sample sites collected for grain size analysis. 


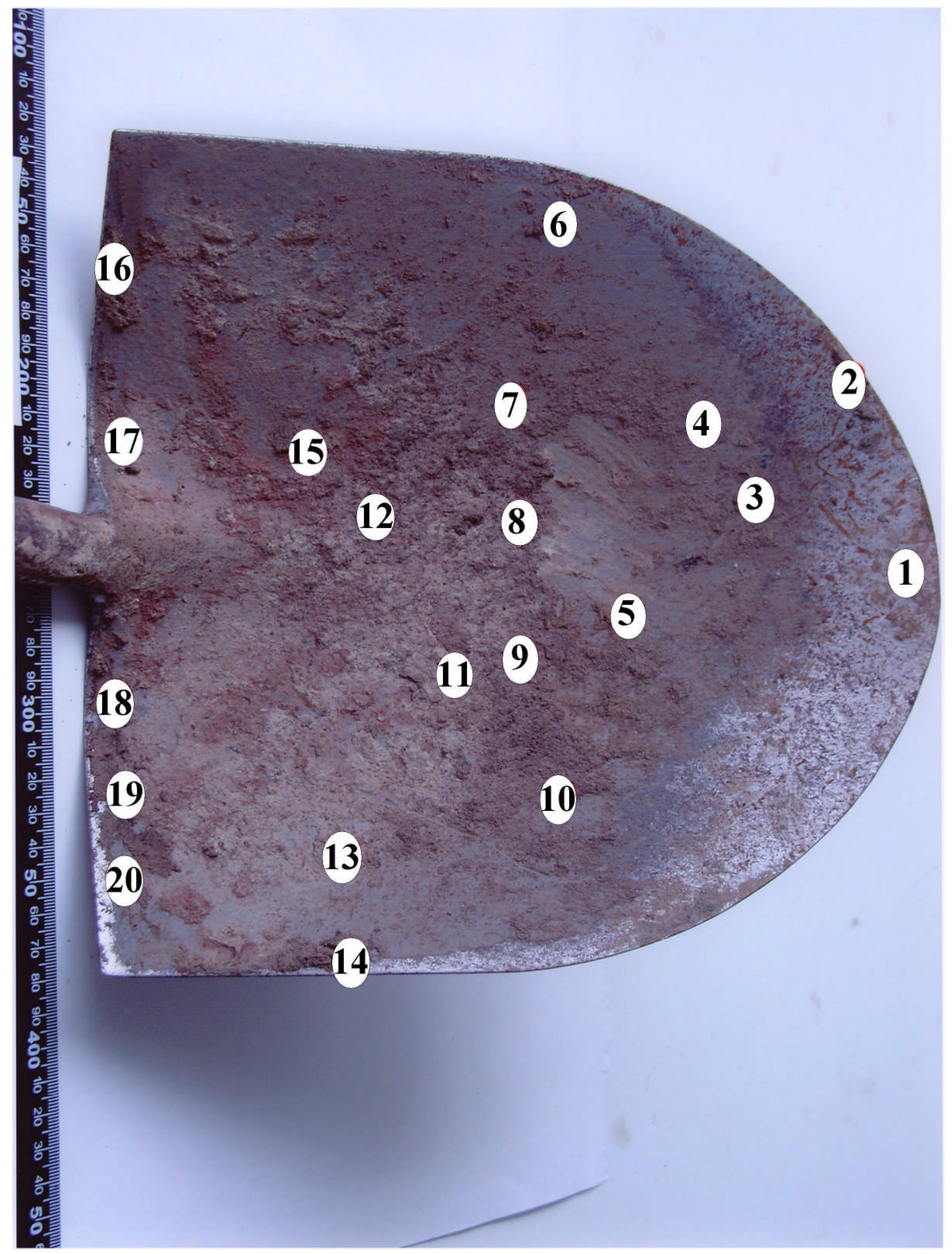

Figure 2 Spade 2 showing adhering mud and the twenty sample sites collected for grain size analysis. 


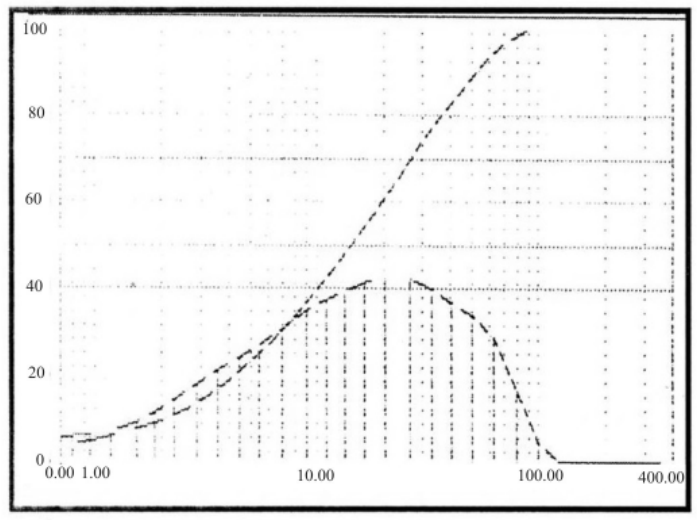

A.

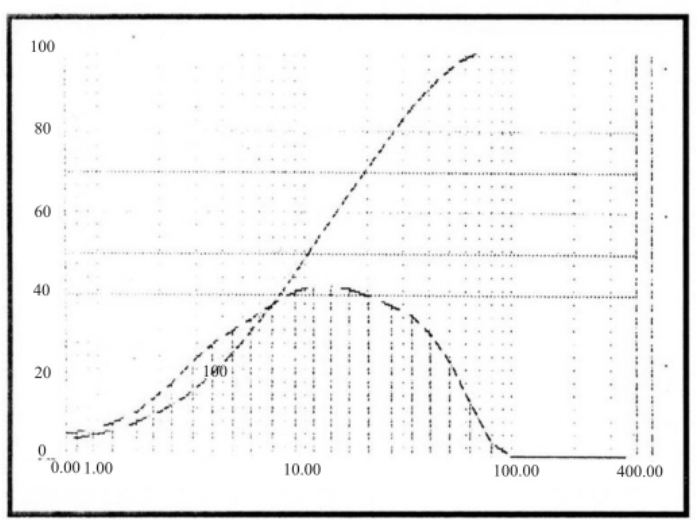

C.

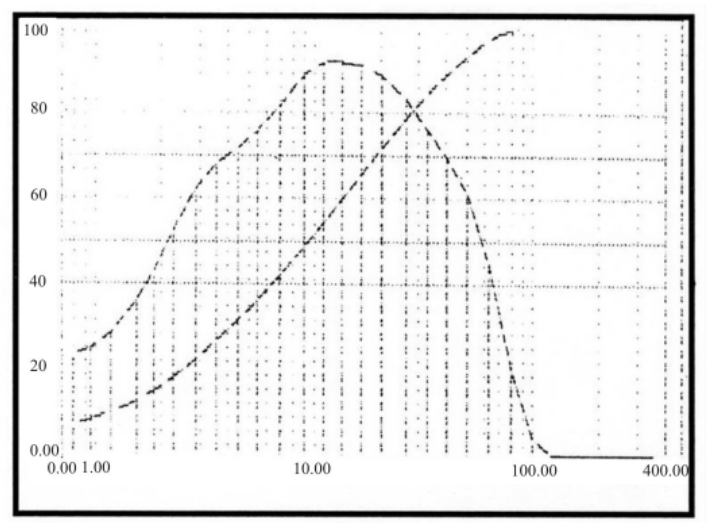

B.

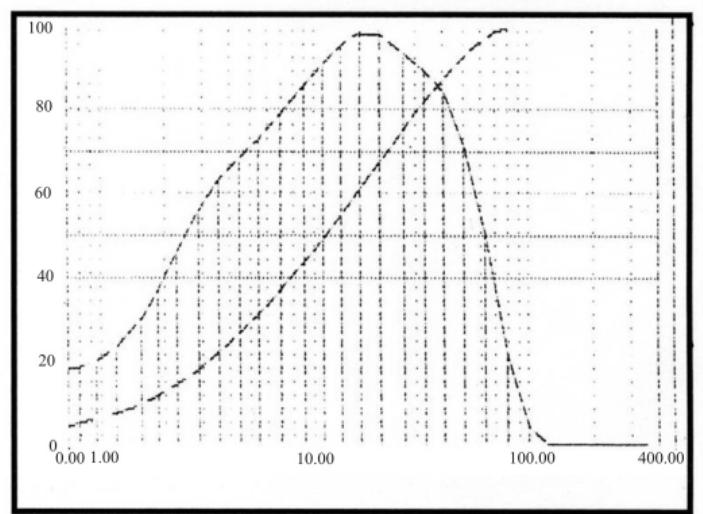

D.

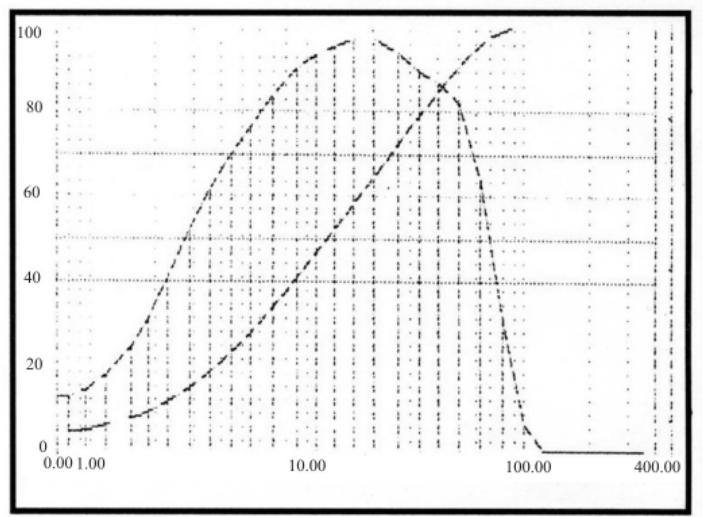

E.

Figure 3 Grain size distribution histograms and cumulative curves portraying the two types of grain size distribution found at A and B: the badger sett site; C and D: spade 2; and E: spade 1. 

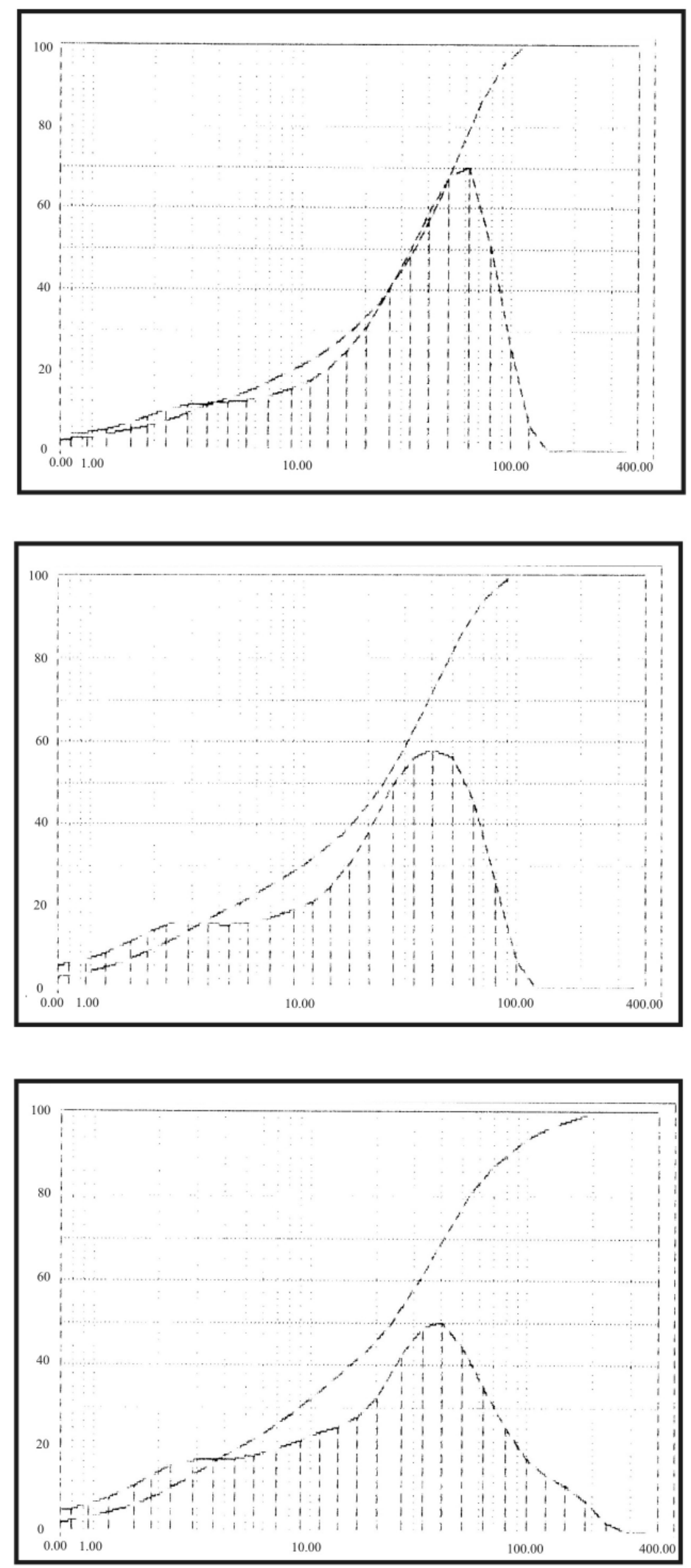

Figure 4 Grain size distribution curves for the sample from the vehicle (top) and the samples from the crime scene (middle and bottom). 


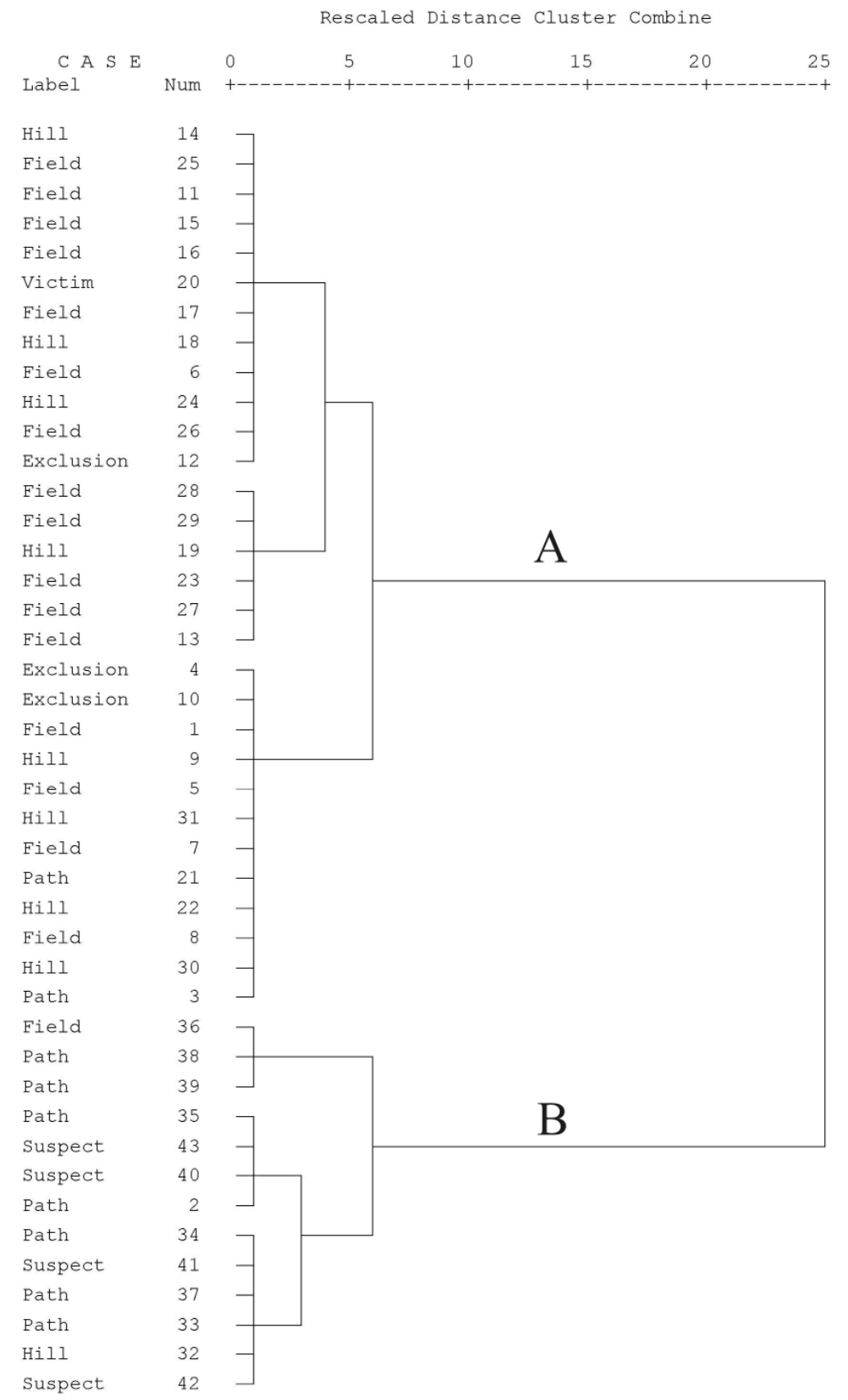

Figure 5 Dendrogram computed from grain size distribution analysis of samples from the hill ridge, the hill path, the field, the suspect, the shoe from the victim and from exclusionary samples. $n=43$. 


\begin{tabular}{|cccccccc|}
\hline Group & $\begin{array}{c}\text { Number of } \\
\text { samples }\end{array}$ & Field & $\begin{array}{c}\text { Hill } \\
\text { (body site) }\end{array}$ & $\begin{array}{c}\text { Path (to } \\
\text { body site) }\end{array}$ & Victim & Suspect & $\begin{array}{c}\text { Exclusion } \\
\text { samples }\end{array}$ \\
\hline A & 30 & $16(94.1)$ & $8(88.9)$ & $2(22.2)$ & $1(100)$ & $0(0)$ & $3(100)$ \\
\hline B & 13 & $1(5.9)$ & $1(11.1)$ & $7(77.8)$ & $0(0)$ & $4(100)$ & $0(0)$ \\
\hline
\end{tabular}

Table 5 Summary of the locations of samples in each of the two groupings from the dendrogram, Figure 5. Figures in brackets indicate the percentage of samples from each location in each cluster grouping.

\section{Eigenvalues}

\begin{tabular}{|l|r|r|r|r|}
\hline Function & Eigenvalue & $\%$ of Variance & Cumulative \% & Canonical Correlation \\
\hline 1 & $2.832(\mathrm{a})$ & 100.0 & 100.0 & .860 \\
\hline
\end{tabular}

a First 1 canonical discriminant functions were used in the analysis.

\section{Wilks' Lambda}

\begin{tabular}{|l|r|r|r|r|}
\hline Test of Function(s) & Wilks' Lambda & Chi-square & df & \multicolumn{1}{c|}{ Sig. } \\
\hline 1 & .261 & 53.740 & 2 & .000 \\
\hline
\end{tabular}

\section{Functions at Group Centroids}

\begin{tabular}{|l|r|}
\hline cluster groupings & \multicolumn{1}{c|}{\begin{tabular}{c} 
Function \\
\hline Group A \\
Group B
\end{tabular}} \\
\hline
\end{tabular}

Unstandardized canonical discriminant functions evaluated at group means

Table 6 Summary of the CDF analysis (derived from SPSS 11.4 for Windows) undertaken to assess the statistical significance of Groups A and B derived in Figure 5 . 